\title{
The Effects of an APOE Promoter Polymorphism on Human Cortical Morphology during Nondemented Aging
}

\author{
Yaojing Chen, ${ }^{1,2 \star}$ Peng Li, ${ }^{3 \star}$ Bin Gu, ${ }^{1 \star}$ Zhen Liu, ${ }^{1,2}$ Xin Li, ${ }^{1,2}$ Alan C. Evans, ${ }^{4}$ Gaolang Gong, ${ }^{1,2,5}$ and Zhanjun Zhang ${ }^{1,2,5}$ \\ ${ }^{1}$ State Key Laboratory of Cognitive Neuroscience and Learning \& IDG/McGovern Institute for Brain Research, Beijing Normal University, Beijing 100875, \\ China, ${ }^{2}$ Beijing Aging Brain Rejuvenation Initiative Centre, Beijing Normal University, Beijing 100875, China, ${ }^{3}$ The Laboratory Research Center of Xiyuan \\ Hospital, China Academy of Chinese Medical Sciences, Beijing 100091, China, ${ }^{4}$ McConnell Brain Imaging Centre, Montreal Neurological Institute, McGill \\ University, Montreal, Quebec H3A 2B4, Canada, and ${ }^{5}$ Center for Collaboration and Innovation in Brain and Learning Sciences, Beijing Normal University, \\ Beijing 100875, China
}

Apolipoprotein $\mathrm{E}(A P O E)$ is the best-known susceptibility gene for AD. It has been well demonstrated that the $\varepsilon 4$ allele of the $A P O E$ gene can affect brain structure/function in nondemented individuals; however, other polymorphisms in the APOE gene have been largely overlooked when assessing the effects of $A P O E$ on the neural system. Rs405509 is a newly recognized AD-related polymorphism located in the $A P O E$ promoter region that can regulate the transcriptional activity of the $A P O E$ gene. To date, it remains unknown whether and how this $A P O E$ promoter polymorphism affects the human brain in aging. Here, for the first time, we investigate the effects of the rs405509 genotype (T/T vs G-allele) on human cortical morphology using a large cohort of nondemented elderly subjects (120 subjects in total; aged 52- 81 years). High-resolution structural MRI was performed; cortical thickness and surface area were analyzed separately. Intriguingly, nondemented carriers of the rs405509 T/T genotype showed an accelerated age-related reduction of thickness in the left parahippocampal gyrus compared with the G-allele carriers. Furthermore, the cortical thickness covariance between the left parahippocampal gyrus and left medial cortex, including the left medial superior frontal gyrus, supplementary motor area, and paracentral lobule, was modulated by the interaction of the rs405509 genotype and age. These novel findings suggest an important role for the APOE promoter polymorphism in the human brain and also provide valuable insights into how the rs 405509 genotype shapes the neural system to modulate the risk of developing AD.

Key words: APOE promoter polymorphism; cortical thickness; nondemented aging; rs405509; surface area; thickness covariance

\section{Introduction}

Apolipoprotein $\mathrm{E}(A P O E)$ is the best-known susceptibility gene for $\mathrm{AD}$ (Farrer et al., 1997). Carriers of the $\varepsilon 4$ allele of the APOE gene are much more likely to develop $\mathrm{AD}$ than noncarriers (Corder et al., 1993). Numerous APOE-related neuroimaging studies have investigated brain structural differences between $\varepsilon 4$ carriers and noncarriers earlier in life, before the development of mild cognitive impairment (MCI) or AD (Bookheimer and Burggren, 2009), and mixed findings have been reported. There were

\footnotetext{
Received May 11, 2014; revised Nov. 26, 2014; accepted Dec. 4, 2014.

Author contributions: Z.Z. designed research; Y.C., P.L., B.G., Z.L., X.L., G.G., and Z.Z. performed research; A.C.E. contributed unpublished reagents/analytic tools; B.G. and G.G. analyzed data; Y.C., G.G., and Z.Z. wrote the paper.

This study is supported by the Beijing New Medical Discipline Based Group (100270569), the 973 program (2013CB837300), the National Science Foundation of China (81322021, 30873458, 81430100 and 81173460), the Project of Institute of Basic Research in Clinical Medicine, China Academy of Chinese Medical Sciences (20175), the Program for New Century Excellent Talents in University (NCET-10-0249), and the Beijing Nova Program (Z121110002512032). We sincerely thank the three anonymous reviewers for their constructive comments that helped to substantially improve the quality of this paper. We also thank Prof Yanchao Bi for her valuable comments and language editing.

*Y.C., P.L., and B.G. contributed equally to the work.

The authors declare no competing financial interests.

Correspondence should be addressed to either Dr. Zhanjun Zhang or Gaolang Gong, State Key Laboratory of Cognitive Neuroscience and Learning, Beijing Normal University, Beijing 100875, China. E-mail: zhang_rzs@bnu.edu.cn or gaolang.gong@bnu.edu.cn.

DOI:10.1523/JNEUROSCI.1946-14.2015

Copyright $\odot 2015$ the authors $\quad 0270-6474 / 15 / 351423-09 \$ 15.00 / 0$
}

studies suggesting a smaller hippocampus in elderly $\varepsilon 4$-carriers (den Heijer et al., 2002) or a thinner entorhinal cortex in child and adolescent $\varepsilon 4$-carriers ( $\sim 7-21$ years) (Shaw et al., 2007); however, other studies reported no significant $\varepsilon 4$-related effects on these mesial-temporal lobe (MTL) structures ( Lemaîitre et al., 2005; Fennema-Notestine et al., 2011).

Notably, the $\varepsilon 4$ allele is not the only AD-related APOE polymorphism. Strong evidence suggested significant effects of polymorphisms within the $A P O E$ promoter region on the $\mathrm{AD}$ occurrence (Lambert et al., 1998a, 2002; Bertram et al., 2007; Lescai et al., 2011). Among these polymorphisms, rs405509 exhibited the strongest impact on neural APOE gene expression and the strongest risk of developing $\mathrm{AD}$, with the $\mathrm{T} / \mathrm{T}$ allele as the risk factor (Lambert et al., 1998b). This polymorphism was also associated with myocardial infarctions, constituting a common risk factor for both neurodegenerative and cardiovascular diseases (Lambert et al., 2000; Ye et al., 2003), and therefore is of particular interest in aging.

The rs405509 polymorphism is putatively functional in nature as a regulator to modify the $A P O E$ gene expression, most probably by modulating specific transcription factor binding activities (Laws et al., 2003). In vitro experiments using electrophoretic mobility shift assays have demonstrated a differential binding activity of the two alleles with multiple transcription factors in 
different cells (e.g., hepatoma cells and neuronal cells; Artiga et al., 1998; Lambert et al., 2004; Maloney et al., 2010). Biochemical analyses of postmortem brain tissue provided direct evidence for its regulatory role in the neural system, showing an association of the $\mathrm{T} / \mathrm{T}$ genotype with a decrease in $A P O E$ expression (i.e., $A P O E$ mRNA; Lambert et al., 1998b, 2005). To date, however, there are no published neuroimaging studies exploring the rs405509 effects on the human brain in vivo, in contrast with the large number of studies performed for the $\varepsilon 4$ allele.

The present study aims to assess the rs405509's effects on cortical morphology during nondemented aging. Investigating nondemented aging individuals is critical to understand the polymorphism's influence on the neural system, which may shed light on how this polymorphism modulates the risk of developing AD. Given the previous findings showing the earliest AD-related neuropathological changes in MTL as well as the most pronounced atrophy in these structures, we hypothesized that the two rs405509 alleles would show MTL morphometric differences in nondemented aging. To test this, structural MRI was performed to measure cortical morphology in a large cohort of nondemented elderly subjects. Cortical thickness and surface area were compared separately, as they show distinct genetic determinants (Panizzon et al., 2009).

\section{Materials and Methods}

\section{Subjects}

Participants were selected from the Beijing Aging Brain Rejuvenation Initiative study, an ongoing longitudinal study examining the brain and cognitive decline in an elderly, community-dwelling sample (aged $>50$ years). All enrolled participants were Han Chinese. Participants qualified for our study if they met the following criteria: (1) no history of neurological or psychiatric disorders; (2) clinically nondemented when the MRI scan was performed; (3) had a qualified high-resolution T1weighted MRI image; (4) no visible abnormalities on the MR images, confirmed by an experienced radiologist; and (5) a successful blood sample for the genotyping analysis. Specifically, the status "clinically nondemented" was determined by using (1) the DSM IV, (2) Petersen's dementia criteria, and (3) Clinical Dementia Rating (score = 0). Accordingly, 120 nondemented subjects (aged 52-81 years; 50 males/70 females) were included in the present study. The age distribution in the entire sample is as follows: 52-61 years, 57 subjects; $62-71$ years, 45 subjects; $71-81$ years, 18 subjects. The protocol was approved by the institutional review board at the Imaging Center for Brain Research at Beijing Normal University. Written consent was obtained from each subject.

\section{Genotyping}

The rs405509 polymorphism (also named Th1/E47cs) is located in the promoter region of the APOE gene. For each subject, we genotyped the rs405509 polymorphism using a TaqMan SNP genotyping assay on a 7900HT Fast Real-Time PCR system (Applied Biosystems). Another two APOE polymorphisms, rs429358 and rs7412, which collectively form the APOE $\varepsilon 2$ (with the rs429358-rs7412 haplotype of T-T), $\varepsilon 3$ (T-C), and $\varepsilon 4$ alleles (C-C), were also genotyped. No other polymorphisms within the $A P O E$ gene were tested at this stage. The sample success rates for all the three polymorphisms were $100 \%$, and the reproducibility of the genotyping was $100 \%$ according to a duplication analysis of at least $10 \%$ of the genotypes. According to our sample, the rs 405509 polymorphism did not show deviations from Hardy-Weinberg equilibrium $(p>0.5)$.

All subjects were divided into two groups according to their rs405509 genotype: $61 \mathrm{G}$-allele (including $55 \mathrm{G} / \mathrm{T}$ and $6 \mathrm{G} / \mathrm{G}$ genotype carriers) and $59 \mathrm{~T} / \mathrm{T}$ carriers. Given the relatively small number of the G/G genotype, we combined the G/G and G/T genotypes into G-allele carriers.

\section{Cognitive tests}

All participants received a widely used screening test for the general cognitive ability, i.e., Minimum Mental State Examination (MMSE), and several classical neuropsychological tests that are representative for as- sessing specific cognitive functions in the research of aging. These tests were as follows: (1) Auditory Verbal Learning Test (AVLT) Delayed Recall, (2) Clock Drawing Test, (3) Category Fluency Test, (4) Boston Naming Test, (5) Symbol Digit Modifying Test, (6) Trail Making Test A, (7) Trail Making Test B, and (8) Stroop Color and Word Test C. The specific neuropsychological test procedures have been previously described (Wang et al., 2013).

\section{MRI acquisition}

High-resolution structural MRI data were acquired from a 3 T Siemens Tim Trio MRI scanner in the Imaging Center for Brain Research, Beijing Normal University. The scanning parameters were as follows: T1weighted MPRAGE sequence, flip angle $9^{\circ}$, acquisition matrix $256 \times 256$, FOV $256 \times 256 \mathrm{~mm}^{2}$, slice thickness $1 \mathrm{~mm}$, voxel size $1 \times 1 \times 1 \mathrm{~mm}^{3}$, TR $1900 \mathrm{~ms}$, and TE $3.44 \mathrm{~ms}$.

\section{Image processing: vertex-based morphology}

We used the CIVET pipeline to measure thickness and surface area on the cortical surface as previously described (Gong et al., 2012). Briefly, the native T1-weighted MR images were first linearly aligned into the stereotaxic space and corrected for nonuniformity artifacts using the N3 algorithm (Sled et al., 1998). This algorithm does not require prior knowledge for the brain tissue classes, and can iteratively estimate both the multiplicative bias field and the distribution of true tissue intensities for automatic correction of intensity nonuniformity in MRI data. The resultant brain images were then automatically segmented into gray matter, white matter, CSF, and background by using a partial volume (PV) classification algorithm, in which a trimmed minimum covariance determinant method was applied for estimating the parameters of the PV effect model; the parameter $\beta$ controlling the relative strength of the Markov random field was set to 0.1 (Tohka et al., 2004). Next, the inner and outer gray matter surfaces were automatically extracted for each hemisphere using the CLASP algorithm (Kim et al., 2005). The individual surfaces were further aligned with a surface template to allow comparisons across subjects at corresponding vertices. Cortical thickness was measured between the two surfaces at 40,962 vertices per hemisphere using the linked distance in the native space (Lerch and Evans, 2005). The middle cortical surface, defined at the geometric center between the inner and outer cortical surfaces, was used to calculate the cortical surface area in the native space (Lyttelton et al., 2009). The thickness/surface area map was further blurred with a $30 \mathrm{~mm}$ surface-based diffusion smoothing kernel (Chung et al., 2003). These methods have been validated using both manual measurements (Kabani et al., 2001) and a population simulation (Lerch and Evans, 2005) and have been widely applied.

\section{Statistical analysis}

To evaluate group differences ( $\mathrm{T} / \mathrm{T}$ vs G-allele carriers) in age and education, two-sample $t$ tests were performed. For gender and the APOE- $\varepsilon 4$ genotype, the $\chi^{2}$ test was applied. For each cognitive test, we used a GLM to determine whether there was a significant age $\times$ group interaction. If not, the main group effect was assessed after excluding the interaction term (Engqvist, 2005).

For all cortical analyses, to correct for multiple vertex-wise comparisons, a random field theory (RFT)-based method was applied at the cluster level (Taylor and Adler, 2003), and cortical clusters surviving an FWE-corrected $p<0.05$ were considered as significant. All these statistical procedures were implemented using SurfStat (http://www.math. mcgill.ca/keith/surfstat/). Here, we first tested the "APOE- $\varepsilon 4$ genotype $\times$ group" and the "gender $\times$ age $\times$ group" interactions across the cerebral cortex, respectively, but no significance was found; therefore, these interaction terms were excluded in the following GLM analyses.

rs405509 genotype $\times$ age or rs405509 genotype $\times$ gender interaction effect on cortical morphology. We first assessed the effect of the rs405509 genotype $\times$ age interaction on cortical thickness and surface area at each vertex. Specifically, a GLM with "age," "group," and "group $\times$ age" as predictor variables was first applied across the entire cerebral cortex, wherein gender, education, intracranial volume (ICV), and APOE- 84 genotype were included as covariates and cortical clusters with an FWEcorrected $p<0.05$ were considered as significant. For the remaining cortical vertices showing no significant group $\times$ age interaction, we fur- 


\begin{tabular}{|c|c|c|c|c|}
\hline & \multirow[b]{2}{*}{$\mathrm{T} / \mathrm{T}$ carrier } & \multirow[b]{2}{*}{ G-allele carrier } & \multirow{2}{*}{$\frac{\text { Main group effect }}{p \text { value (uncorrected) }}$} & \multirow{2}{*}{$\frac{\text { Group } \times \text { age interaction }}{p \text { value (uncorrected) }}$} \\
\hline & & & & \\
\hline \multicolumn{5}{|l|}{ Demographic } \\
\hline Number & 59 & 61 & N/A & $\mathrm{N} / \mathrm{A}$ \\
\hline Age (years) & $63.8 \pm 7.0$ & $63.2 \pm 7.0$ & 0.61 & $\mathrm{~N} / \mathrm{A}$ \\
\hline Education (years) & $10.6 \pm 3.2$ & $10.1 \pm 3.1$ & 0.36 & $\mathrm{~N} / \mathrm{A}$ \\
\hline Gender (male/female) & $26 / 33$ & $24 / 37$ & 0.60 & N/A \\
\hline APOE- $\epsilon 4$ genotype $(+/-)$ & $18 / 41$ & $10 / 51$ & 0.07 & N/A \\
\hline \multicolumn{5}{|l|}{ Cognitive assessment } \\
\hline MMSE & $26.4 \pm 2.2$ & $27.3 \pm 1.8$ & $\mathrm{~N} / \mathrm{A}$ & $0.01^{*}$ \\
\hline \multicolumn{5}{|l|}{ Specific cognitive test } \\
\hline AVLT Delayed Recall & $3.2 \pm 2.1$ & $4.1 \pm 2.7$ & 0.06 & 0.65 \\
\hline Clock Drawing Test & $24.1 \pm 5.3$ & $24.5 \pm 3.7$ & 0.55 & 0.61 \\
\hline Category Fluency Test & $39.9 \pm 10.0$ & $42.5 \pm 8.2$ & 0.11 & 0.55 \\
\hline Boston Naming Test & $22.0 \pm 3.9$ & $23.3 \pm 3.6$ & $0.03^{*}$ & 0.59 \\
\hline Symbol Digit Modifying Test & $30.7 \pm 12.1$ & $32.6 \pm 10.9$ & 0.30 & 0.84 \\
\hline Trail Making Test A & $65.2 \pm 30.7$ & $63.6 \pm 23.0$ & 0.96 & 0.49 \\
\hline Trail Making Test B & $219.4 \pm 107.4$ & $190.2 \pm 76.2$ & 0.07 & 0.81 \\
\hline Stroop Color and Word Test C & $84.8 \pm 36.2$ & $78.5 \pm 26.0$ & 0.32 & 0.22 \\
\hline
\end{tabular}

${ }^{*} p<0.05$ (uncorrected).

ther tested the main group effect after removing the group $\times$ age interaction term in the linear model and therefore set the control for age, gender, education, ICV, and $A P O E-\varepsilon 4$ genotype. The RFT-based correction for multiple vertex-wise comparisons was also applied (FWEcorrected $p<0.05)$.

We further assessed the effect of the rs405509 genotype $\times$ gender interaction on cortical thickness and surface area. Specifically, a GLM with "gender," "group," and "group $\times$ gender" as predictor variables was used, wherein age, education, ICV, and $A P O E-\varepsilon 4$ genotype were included as covariates. Similarly, cortical clusters with an FWE-corrected $p<0.05$ were significant.

rs405509 genotype $\times$ age interaction effect on thickness-cognition relationship. For the cortical clusters showing a significant rs405509 genotype $X$ age interaction for thickness (no such clusters were found for the surface area metric), we further tested whether the thickness-cognition relationship was also influenced by the rs 405509 genotype $\times$ age interaction. Specifically, for each cognitive test, we applied a GLM with "thickness," "age," "group," "thickness $\times$ age," "group $\times$ thickness," "group $\times$ age," and "thickness $\times$ group $\times$ age" as predictor variables. Additionally, gender, education, ICV, and APOE- $\varepsilon 4$ genotype were included as covariates. The three-way interaction term thickness $\times$ group $\times$ age was evaluated, representing the effect of the rs 405509 genotype $X$ age interaction on the relationship between the cluster thickness and cognitive scores. If the three-way thickness $\times$ group $\times$ age interaction was not significant, we performed a simpler GLM with thickness, group, and thickness $\times$ group as predictor variables and age, gender, education, ICV, and $A P O E-\varepsilon 4$ genotype as covariates. In this model, the thickness $\times$ group interaction was tested, representing the effect of the rs405509 genotype on the thickness-cognition relationship.

rs405509 genotype $\times$ age interaction effect on cortical thickness covariance. The covariance of cortical thickness between different vertices or regions is neurobiologically meaningful (Gong et al., 2012; Evans, 2013). Therefore, we further investigated how the rs405509 genotype, together with age, influences thickness covariance between the above-identified cortical cluster (i.e., the seed region) and other vertices on the cortical surface. Specifically, a GLM was applied for the thickness at each vertex, in which "seed thickness," "age," "group," "seed thickness $\times$ age," "seed thickness $\times$ group," "age $\times$ group," and "seed thickness $\times$ group $\times$ age" served as predictor variables. Gender, education, brain size, and $A P O E-\varepsilon 4$ genotype were included as covariates in the model. For each subject, the seed thickness was defined as the mean thickness of vertices within the seed region (i.e., the cluster identified in step 1). The three-way seed thickness $\times$ group $\times$ age interaction was assessed for each vertex, and the RFT-based correction for multiple vertex-wise comparisons was also applied (FWE-corrected $p<0.05$ ). The surviving cluster in this analysis indicates a significant effect of the rs405509 genotype $\times$ age interaction on the thickness correlation between the cluster and the seed region.

\section{Results}

The demographic data and cognitive scores are summarized in Table 1. The rs405509 T/T genotype group did not differ significantly from the G-allele carriers in age, education, gender, or $A P O E-\varepsilon 4$ genotype.

Among the cognitive scores, only MMSE showed a significant age $\times$ group interaction $(F=6.49, p=0.01)$, and post hoc analysis revealed a faster age-related decrease in the MMSE score in $\mathrm{T} / \mathrm{T}$ carriers relative to $\mathrm{G}$-allele carriers. There were no significant age $\times$ group interactions for any of the specific cognitive tests. For the main group effect, $\mathrm{T} / \mathrm{T}$ carriers performed significantly worse than G-allele carriers in Boston Naming Test $(F=4.94$, $p=0.03$ ). A trend of poorer performance in $\mathrm{T} / \mathrm{T}$ carriers was also observed in AVLT Delayed Recall $(F=3.58, p=0.06)$ and Trail Making Test $\mathrm{B}(F=3.25, p=0.07)$. Notably, the significant cognitive results were not corrected for multiple comparisons and therefore should be regarded as exploratory in nature.

\section{Rs405509 genotype $\times$ age interaction effect on the thickness of the left parahippocampal gyrus}

The ICV showed no significant group $\times$ age interaction $(F=$ $1.16, p=0.28)$ and no group differences $(F=2.08, p=00.15)$ between the T/T and G-allele carriers.

For the mean thickness of the entire cerebral cortex, no significant group $\times$ age interaction was observed $(F=0.62, p=0.43)$. Additionally, there was no group difference $(F=0.84, p=0.36)$ between the T/T and G-allele carriers. The vertex-based $F$ map for the group $\times$ age interaction on thickness is illustrated in Figure 1A. After RFT-based correction for multiple comparisons, only one cortical cluster, located on the left parahippocampal gyrus (PHG; Fig. 1B), showed a significant group $\times$ age interaction effect (FWE-corrected $p=0.007$ ). The significant group $\times$ age interaction here indicates a group difference in the regression slopes between thickness and age. Specifically, the scatter plot revealed that the thickness of this cluster in the T/T carriers decreased faster with increasing age (Fig. $1 C$ ). We further examined partial correlations between age and thickness of the left PHG cluster, separately for the T/T and G-allele carriers, after control- 

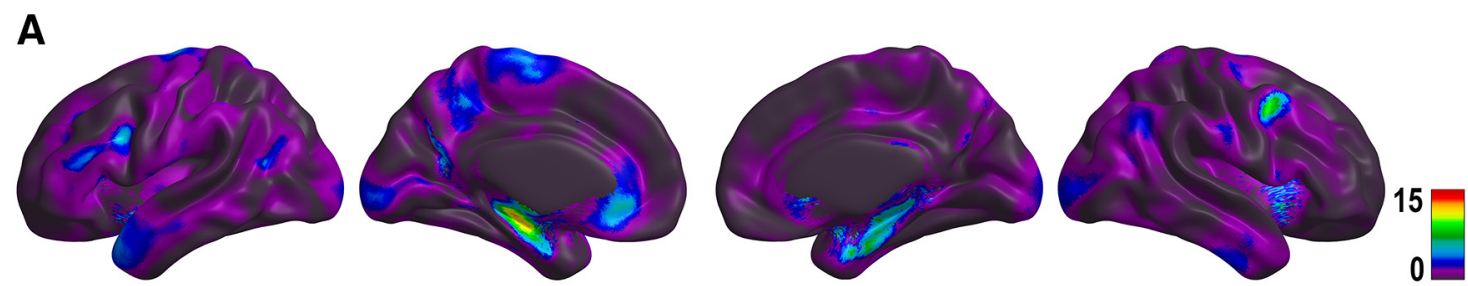

B

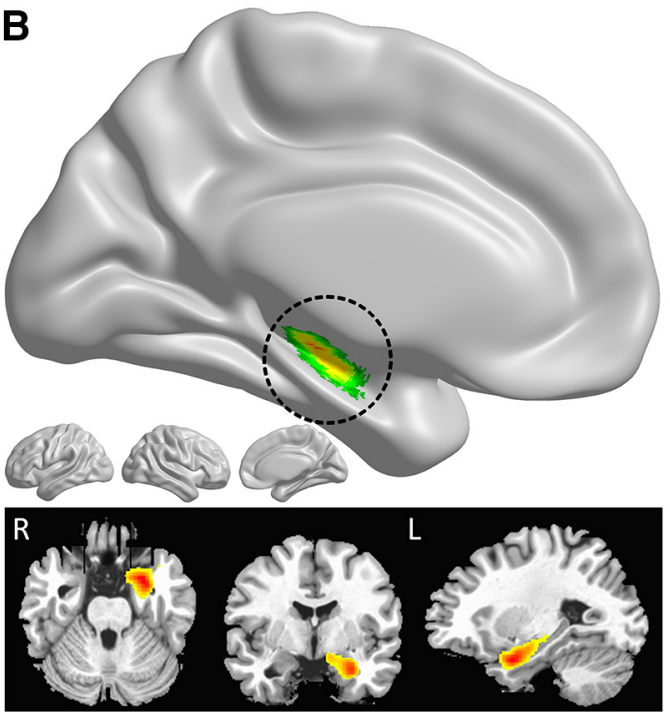

C

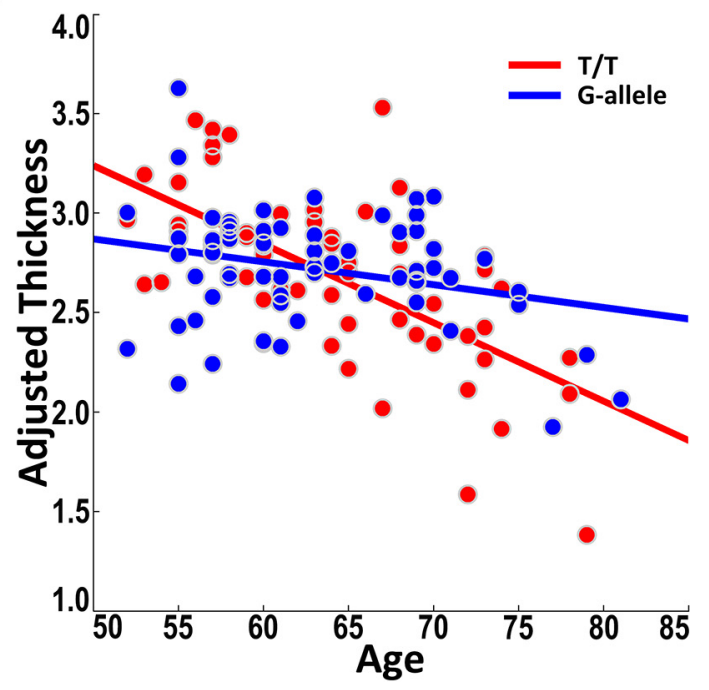

Figure 1. The rs 405509 genotype $\times$ age interaction effect on cortical thickness. $A$, The $F$ statistic map for the rs 405509 genotype $\times$ age interaction across the entire cerebral cortex. $B$, The significant cluster (FWE-corrected $p=0.007$ ) after the RFT-based correction. The cluster is located on the left PHG. Additional VBM analyses also showed a significant rs405509 genotype $\times$ age interaction in the left PHG. C, The scatter plot of the rs 405509 genotype $\times$ age interaction for the left PHG cluster. Specifically, the partial residual plot was drawn to illustrate how the left PHG thickness changes within the actual range of age, after adjusting for gender, education, ICV, and APOE- $\varepsilon 4$ genotype. This was implemented by the function of "surfstatplot" in SurfStat (http://www. math.mcgill.ca/keith/surfstat/). R, right; L, left.

ling for gender, education, ICV, and $A P O E-\varepsilon 4$ genotype. The correlation coefficient was significantly negative for both $\mathrm{T} / \mathrm{T}$ $(r=-0.62, p<0.001)$ and G-allele carriers $(r=-0.30, p=$ $0.02)$. In the remaining cerebral cortex, we found no significant clusters for the main group effect.

To validate this finding, we divided all 120 subjects into two agematched subgroups (60 subjects for each subgroup) and evaluated the split-half reliability of the group $\times$ age interaction on the cluster thickness. The two subgroups both replicated the significant interactions of the whole cohort (subgroup 1: $F=7.09, p=0.01$; group 2: $F=7.56, p=0.008$ ). In addition, a voxel-based morphometry (VBM) analysis was conducted. In accord with the prior results, the left PHG showed a significant group $\times$ age interaction on gray matter volume (FWE-corrected $p<0.05$; Fig. $1 B$ ).

For surface area, there was no significant group $\times$ age interaction on total cortical area $(F=1.86, p=0.18)$, and no significant group difference was found $(F=0.33, p=0.57)$. At the vertex level, we did not find cortical clusters with a significant interaction or a significant main group effect. Consequently, no further analyses regarding the rs405509 genotype $\times$ age interaction on the surface area-behavior relationship or surface area covariance were performed.

\section{Rs405509 genotype $\times$ gender interaction effect on} cortical thickness

The $F$ map for the group $\times$ gender interaction on thickness is illustrated in Figure $2 A$. There were four significant cortical clusters (Fig. 2B), which were located around (1) the left parahippocampal and inferior temporo-occipital cortex (FWE-corrected $p<0.0001$ ), (2) the left superior occipital and mesial occipitalparietal cortex (FWE-corrected $p<0.0001$ ), (3) the right parahippocampal and mesial temporal-occipital cortex (FWE-corrected $p<0.0001$ ), and (4) the left superior and middle frontal cortex (FWE-corrected $p=0.02$ ). The significant group $\times$ gender interaction here indicates a gender difference in the thickness difference between the T/T and G-allele carriers. The bar chart revealed a greater thickness of the G-allele carriers in males but a greater thickness of the $\mathrm{T} / \mathrm{T}$ carriers in females, and this pattern was similar across the four clusters (Fig. 2C).

For surface area, there was a significant group $\times$ gender interaction on total cortical area $(F=10.68, p=0.001)$. However, we did not observe any significant local cortical clusters showing such a significant interaction.

The rs405509 genotype effect on the thickness-MMSE relationship in the left PHG

For the above cluster located in the left PHG, no significant thickness $\times$ group $\times$ age interaction was found for any of the cognitive tests. After covarying the age factor, the MMSE showed a significant group $\times$ thickness interaction $(F=4.69, p=0.03)$, suggesting a significant group difference in regression slopes (Fig. 3). Specifically, the T/T carriers had a steeper slope for the correlation between the MMSE and thickness. However, the partial correlations between MMSE and thickness of the left PHG cluster, separately for the two genotype groups, after controlling for age, gender, education, ICV, and $A P O E-\varepsilon 4$ genotype, did not reach the significance level (T/T carriers: $r=0.21, p=0.12$; G-allele carriers: $r=-0.002, p=0.99)$. 
A

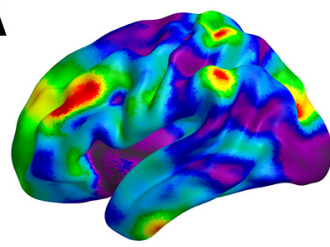

B

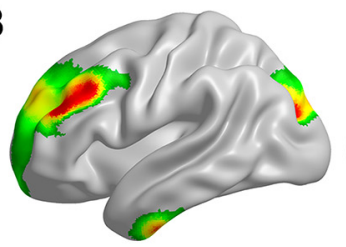

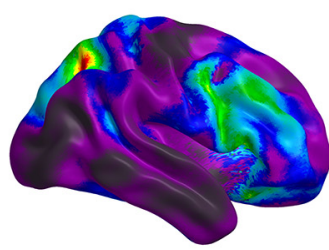

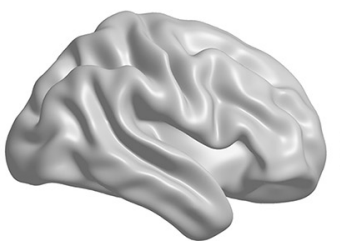

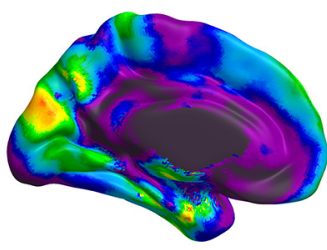
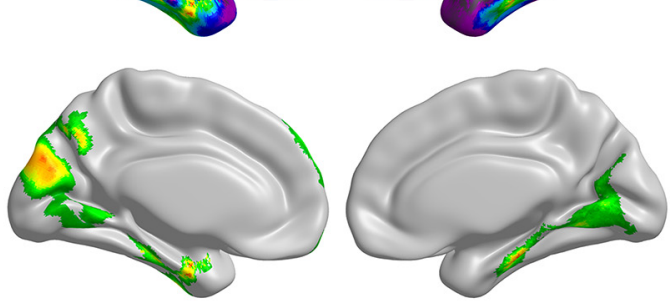

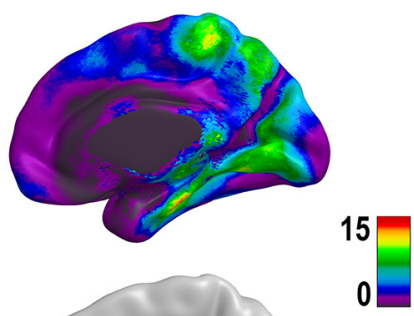

C

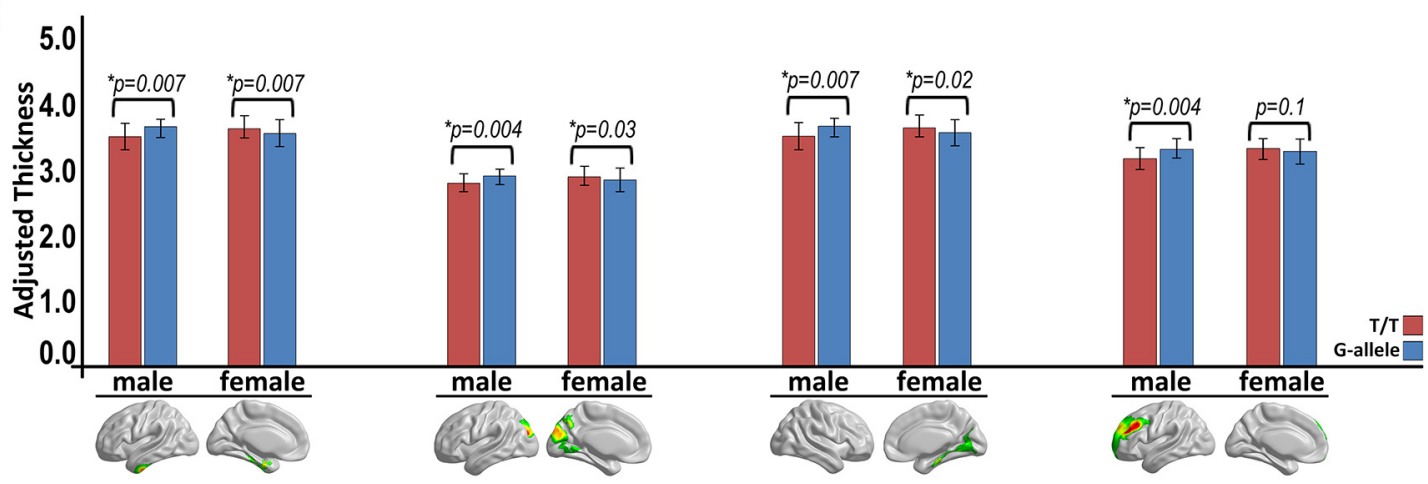

Figure 2. The rs 405509 genotype $\times$ gender interaction effect on cortical thickness. $A$, The $F$ statistic map for the $r 405509$ genotype $\times$ gender interaction across the entire cerebral cortex. $\boldsymbol{B}$, The significant four cortical clusters after the RFT-based correction. C, The bar charts of the rs 405509 genotype $\times$ gender interaction for all the clusters. The corresponding cluster was displayed below the bar chart. The bar charts were drawn using "surfstatplot," with age, education, ICV, and APOE- $\varepsilon 4$ genotype adjusted. ${ }^{*} p<0.05$.

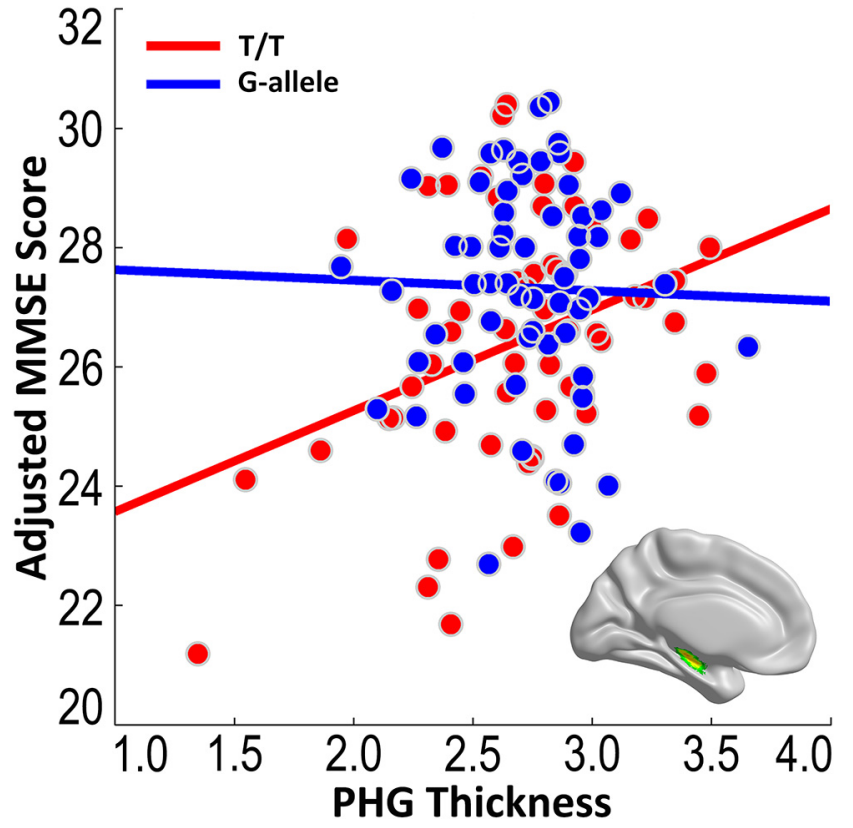

Figure 3. The effect of the rs405509 genotype on the thickness-MMSE relationship. The effect of the rs405509genotypeontherelationship between thickness andMMSEintheduster oftheleftPHGisindicated by a significant "rs405509 genotype $\times$ thickness" interaction on the MMSEscore $(F=4.69, p=0.03)$. The partial residual is plotted accordingly, with age, gender, education, ICV, and APOE- 84 genotype adjusted.

Rs405509 genotype $\times$ age interaction effect on the thickness covariance of the left PHG

Figure $4 A$ illustrates the $F$ map for the three-way seed thickness $\times$ group $\times$ age interaction, representing the rs 405509 genotype $X$ age interaction effect on the thickness covariance seeding from the left PHG cluster. After the RFT-based correction, only one large cluster covering the medial part of the left cerebral cortex (Fig. $4 B$ ) showed such a significant seed thickness $\times$ age $\times$ group interaction (FWE-corrected $p=0.003$ ). Visibly, there are three local significant peaks in this cluster, located on the left medial superior frontal gyrus (SFGmed), supplementary motor area (SMA), and paracentral lobule (PCL). Because there is no simple way to plot a three-way interaction with two continuous variables (i.e., seed thickness and age), we first divided all subjects into two age subgroups: a low-age group with age $\leq 63$ years ( 60 subjects in total: $52-57$ years, 30 subjects; $58-63$ years, 30 subjects) and a high-age group with age $>63$ years (60 subjects in total: $64-69$ years, 35 subjects; $70-75$ years, 19 subjects; 76-81 years, 6 subjects), and then plotted the three-way interaction accordingly. Notably, for a better spatial specificity, we made the scatter plots for the entire cluster and three local peaks, respectively. As illustrated in Figure $4 B$, within the high-age group, the entire cluster exhibited a difference in the slope of mean thickness correlation with the left PHG cluster between the T/T and G-allele carriers, with $\mathrm{G}$-allele carriers showing a steeper slope. However, there was no obvious slope difference between rs405509 genotypes in the low-age group. The scatter plots for the three local peaks consistently exhibited a very similar pattern with the one for the entire cluster (Fig. 4C). In these plots, the "thickness" for the local peak at the left SFGmed, SMA, and PCL was computed as the mean thickness of vertices within a $3 \mathrm{~mm}$ sphere of the peak for each subject.

We further assessed partial correlations of thickness between the seed and target regions, separately for the T/T and G-allele carriers in the low-age and high-age subgroups, after controlling for gender, 


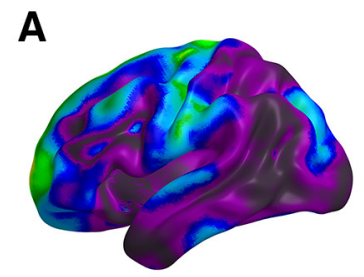

B

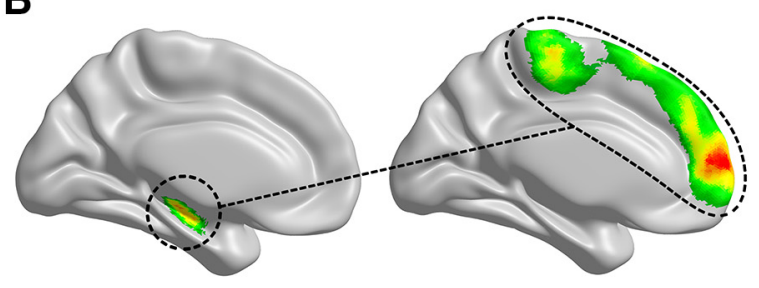

C
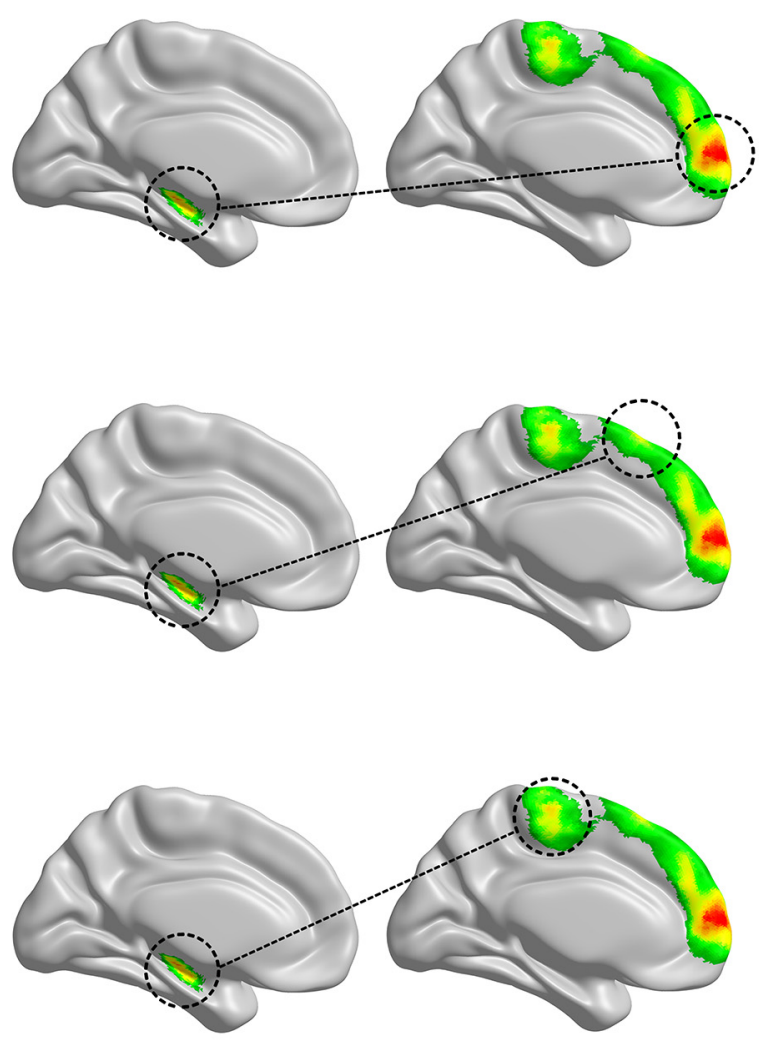
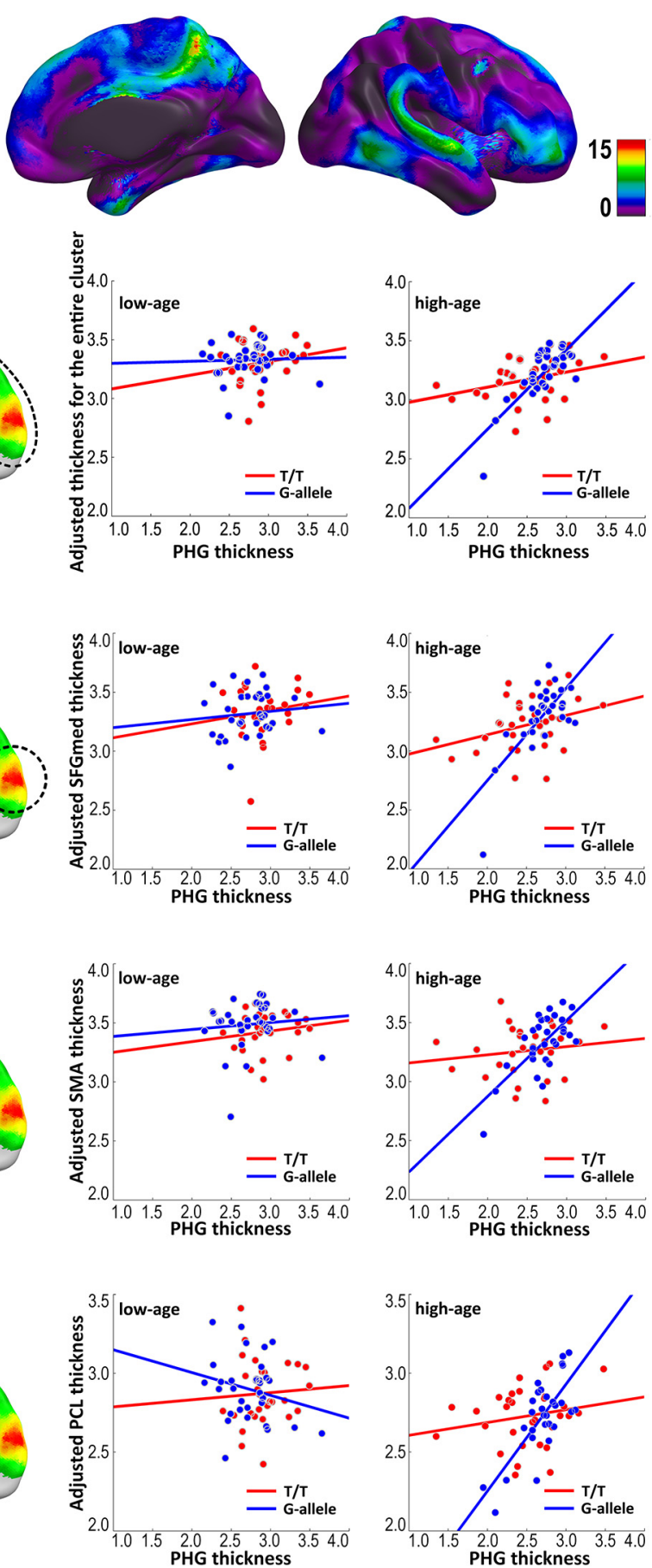

Figure 4. The rs 405509 genotype $\times$ age interaction effect on thickness correlation. $A$, The $F$ statistic map for the seed thickness $\times$ rs 405509 genotype $\times$ age interaction across the entire cerebral cortex. The cluster on the left PHG identified in Figure 1 was chosen as the seed region. $\boldsymbol{B}$, The significant cluster (FWE-corrected $p=0.003$ ) after the RFT correction. $\boldsymbol{C}$, The cluster mainly covers the medial part of the left hemisphere, and three local statistically significant peaks are located around the left SFGmed (row 1), SMA (row 2), and PCL (row 3). After dividing all subjects into low-age (60 subjects, $\leq 63$ years) and high-age ( 60 subjects, $>63$ years) groups, the three-way interactions for the entire cluster and three statistical local peaks were plotted using the "surfstatplot," with gender, education, ICV, and APOE- $\varepsilon 4$ genotype adjusted.

education, ICV, and APOE- 84 genotype. When using the mean thickness of the entire large cluster in the left medial cortex, there was a significant partial correlation only in the G-allele carriers of the high-age subgroup $(r=0.76, p<0.001)$, but not in the other subgroups (the T/T carriers of the high-age subgroup: $r=0.25, p=0.22$; the G-allele carriers of the low-age subgroup: $r=0.03, p=0.86$; the T/T carriers of the low-age subgroup: $r=0.29, p=0.17$ ). Consistently, for the three local peaks, the correlation coefficients were significantly positive in the G-allele carriers of the high-age subgroup (the left SFGmed: $r=0.67, p=0.001$; the left SMA: $r=0.64, p=$ 0.001 ; the left PCL: $r=0.75, p=0.001$ ), but nonsignificant in the T/T carriers of the high-age subgroup (the left SFGmed: $r=0.26$, $p=0.18$; the left SMA: $r=0.06, p=0.77$; the left PCL: $r=0.18 ; p=$ 0.38 ). In the low-age subgroup, no significant correlation was observed for either the G-allele (the left SFGmed: $r=0.11, p=0.57$; the left SMA: $r=0.10, p=0.68$; the left PCL: $r=-0.17, p=0.38$ ) or 
T/T carriers (the left SFGmed: $r=0.20, p=0.36$; the left SMA: $r=$ $0.27, p=0.21$; the left PCL: $r=0.12, p=0.58$ ).

\section{The comparison of the PHG thickness between $\varepsilon 4$-carriers and noncarriers}

Despite the very unbalanced sample size in our cohort, we performed an exploratory group comparison between the $\varepsilon 4$ carriers (28 subjects) and noncarriers (92 subjects). The mean thickness of the left PHG cluster identified above showed no significant group differences $(F=0.07, p=0.80$; after covarying gender, education, ICV, and age). In addition, using prior mask for PHG in the AAL atlas, we extracted the mean thickness of left/right PHG for each subject. In consistency, there were no significant thickness differences in the entire PHG (left: $F=3.85$, $p=0.052$; right: $F=0.27, p=0.60$; after covarying gender, education, ICV, and age). Notably, covarying the rs405509 genotype did not change the results.

\section{Discussion}

Using a large cohort, the present study investigated the effects of the rs405509 polymorphism within the APOE promoter region on cortical thickness and surface area during nondemented aging. Intriguingly, the rs $405509 \mathrm{~T} / \mathrm{T}$ carriers showed an accelerated age-related reduction of thickness in the left PHG compared with G-allele carriers. Furthermore, the thickness covariance between the left PHG and left medial cerebral cortex, including the left SFGmed, SMA, and PCL, was modulated by the interaction of rs405509 genotype and age. The present study provides direct evidence for a significant role of the APOE promoter polymorphism in the neural system.

Many neuroimaging studies have assessed the APOE- 84 impact on neurophysiology or neuroanatomy in healthy subjects. To date, however, other polymorphisms in the APOE gene have been largely overlooked when evaluating the effects of $A P O E$ on the human brain. To our knowledge, the present investigation represents the first neuroimaging study to explore how the polymorphism within the APOE promoter region affects the human brain. Therefore, our findings are of particular interest for disentangling the functions of $A P O E$ promoter polymorphisms in the neural system. More generally, the current study highlights a novel genetic factor, i.e., rs405509, for understanding individual differences in the human brain, particularly during nondemented aging.

\section{The effects of rs 405509 on cortical morphology and its relationship with cognition}

Cortical thinning has been well characterized in aging subjects. Of interest, the current study demonstrated a faster thinning of the left PHG for the rs405509 T/T carriers than G-allele carriers, with a similar trend observed in the right PHG (Fig. 1). Many cognitive processes, including visuospatial processing and episodic memory, are putatively associated with the PHG, and contextual associative processing was recently proposed as the core function for this region (Aminoff et al., 2013). The accelerated thinning of the PHG in T/T carriers is likely to be the neural substrate underlying the faster decline of general cognitive abilities in the T/T carriers, as indicated by a significant age $\times$ group interaction (uncorrected) for the MMSE score.

The PHG is one of the most frequently identified regions with degenerative pathology in $\mathrm{AD}$. Volumetric atrophy or thinning of the PHG has been observed in AD (Lerch et al., 2005, 2008), MCI patients (Yao et al., 2012), and APOE- 84 carriers (Honea et al., 2009). In the pre-AD stage, significant atrophy occurred in the left PHG before the right (Rusinek et al., 2004; Yao et al., 2012), which is compatible with the leftward results in our study. It has been hypothesized that a "severe degeneration" in the PHG (e.g., reduced thickness/volume) is a sufficient and necessary condition for MCI to develop into AD: MCI patients with severe PHG degeneration will much more readily develop $\mathrm{AD}$ and vice versa (Visser et al., 2002). Therefore, it is possible that "severe degeneration" of the PHG is one of the preconditions for developing $\mathrm{AD}$ in nondemented elderly adults. The T/T carriers showed a faster decline of the PHG, as indicated by accelerated age-related thinning, which likely leads to less time or a greater likelihood of reaching the status of "severe degeneration" of the PHG for T/T carriers, therefore increasing the risk of $\mathrm{AD}$.

The APOE- $\varepsilon 4$ allele also influences PHG thickness in nondemented elderly adults, with APOE- $\varepsilon 4$ carriers showing less PHG volume than noncarriers (Honea et al., 2009). These findings raise the question of whether the two APOE polymorphisms affect the PHG independently. In fact, it remains controversial whether the rs $405509 \mathrm{~T} / \mathrm{T}$ genotype is an independent risk factor for AD (Lambert et al., 1998b; Beyer et al., 2002) or whether it interacts with the $\varepsilon 4$ allele and modulates the risk of $\mathrm{AD}$ (Laws et al., 2003). In the present study, we statistically tested the interaction of the rs405509 and $\varepsilon 4$ genotypes on cortical thickness and surface area but found no significant results. Additionally, controlling for the $A P O E-\varepsilon 4$ genotype did not change our statistical results compared with not controlling for the APOE- 84 genotype. Particularly, our exploratory comparison between the $\varepsilon 4$-carriers and noncarriers showed no difference in PHG thickness. The rs405509 effect on PHG thickness in aging seems independent from the $\varepsilon 4$ status, favoring an independent role of the rs405509 $\mathrm{T} / \mathrm{T}$ genotype for the risk of developing AD. However, the number of $\varepsilon 4$ allele carriers was much less than that of noncarriers in our cohort, leading to a lower statistical power. Further studies with a larger sample size as well as molecular neurobiological techniques are needed to evaluate this speculation.

Interestingly, our data also showed that the thickness differences between rs405509 genotypes were affected by gender, which did not change as age increases. The gender factor has shown a substantial impact in the development and progression of MCI and AD (Mielke et al., 2014). Our currently observed interactions between rs 405509 genotype and gender further suggest a complex mechanism involving both genetic and hormonal factors, possibly underlying the AD-risk modulation. More generally, this finding highlights an important role of genetic factors on sexual dimorphism in the human brain (Sowell et al., 2007).

Finally, we observed a significant difference in the relationship between thickness of the left PHG and MMSE score. Specifically, the MMSE showed a decreasing trend with thinning of the left PHG in the T/T carriers (i.e., a steeper slope), but not in the G-allele carriers. Interestingly, a recent study also demonstrated changes in the relationship between thickness and cognitive scores due to X-chromosome loss (Xie et al., 2014). These findings highlight the necessity of taking brain-gene interactions into account when studying individual variation in human cognitive abilities.

\section{The effects of rs 405509 on cortical thickness covariance}

The covariance of cortical thickness is neurobiologically meaningful (Evans, 2013). Maps of cortical thickness covariance have shown similar patterns as maps of corticocortical white matter connectivity derived from diffusion MRI (Lerch et al., 2006) or maps of corticocortical "functional connectivity" derived from functional MRI techniques (Chen et al., 2008). There are changes 
of cortical thickness covariance in brain diseases such as $\mathrm{AD}(\mathrm{He}$ et al., 2008) and during normal development (Raznahan et al., 2011). Particularly, cortical regions with a high covariance in thickness show strong shared genetic influences on thickness (Schmitt et al., 2008). The observed rs405509 effects on cortical thickness covariance between the left PHG and left medial cortex in aging provide direct support for genetic influences on anatomical covariance (Evans, 2013).

Specifically, in the early stages of aging, there was no evident thickness covariance between the left PHG and left medial cortex in the two rs405509 genotype groups. However, this covariance emerged as age increased but only in the G-allele carriers. The age-related changes of the thickness covariance in the G-allele carriers might relate to the spatiotemporal dynamics of APOE gene expression and transcript variants in the human brain (Kang et al., 2011). One possibility is that specific functions of the rs405509 G-allele in the neural system can only be triggered at late age, ultimately leading to a thickness covariance afterward. Notably, the underlying mechanisms can only be speculative at this point, and specific investigations are needed. Finally, given the fact that thickness correlations can partly reflect underlying fiber connections (Gong et al., 2012), one may expect a nontrivial impact of the rs 405509 polymorphism on specific white-matter tracts linking these regions, which can be tested in future studies by using diffusion MRI.

\section{Limitations and future works}

First, it is very important in the future to validate our findings by replicating our analyses in a completely independent aging cohort. Also, a longitudinal dataset in aging is highly desired to verify the current results from cross-sectional analyses. Next, other polymorphisms within the APOE promoter regions exist. Due to less positive evidence for their association with $\mathrm{AD}$, particularly in Asian samples, these polymorphisms remain ungenotyped in our sample. However, it would be intriguing to genotype these polymorphisms and evaluate the combinatorial effects of these polymorphisms on cortical morphology. Moreover, it remains unclear if other genes are implicated in the rs405509related effects on cortical morphology, which should also be addressed in future studies. Third, the present study showed no evidence for significant rs405509 effects on cognition (i.e., corrected $p>0.05$ for all cognitive scores). Fuller scales of cognitive tests are warranted to more comprehensively understand related cognitive mechanisms. Particularly, given the observed polymorphism effect on the PHG, more extensive memory tests were desired. Finally, the rs405509 polymorphism likely affects the human brain differently before aging, e.g., in children and adolescences, particularly given our currently observed agedependent effects. Therefore, caution should be exercised when extrapolating our findings across the entire life span.

\section{Conclusion}

The present study demonstrated a significant effect of the rs405509 polymorphism on cortical thickness of the left PHG, with the T/T carriers showing an accelerated thinning during nondemented aging. The thickness covariance of the left PHG was also affected by the interaction of the rs405509 genotype and age. These novel findings suggest an important role for APOE promoter polymorphisms in the human brain and provide valuable insights into how the rs405509 polymorphism shapes the neural system to modulate the risk of developing AD.

\section{References}

Aminoff EM, Kveraga K, Bar M (2013) The role of the parahippocampal cortex in cognition. Trends Cogn Sci 17:379-390. CrossRef Medline

Artiga MJ, Bullido MJ, Sastre I, Recuero M, García MA, Aldudo J, Vázquez J, Valdivieso F (1998) Allelic polymorphisms in the transcriptional regulatory region of apolipoprotein E gene. FEBS Lett 421:105-108. CrossRef Medline

Bertram L, McQueen MB, Mullin K, Blacker D, Tanzi RE (2007) Systematic meta-analyses of Alzheimer disease genetic association studies: the AlzGene database. Nat Genet 39:17-23. CrossRef Medline

Beyer K, Lao JI, Gómez M, Riutort N, Latorre P, Mate JL, Ariza A (2002) The Th1/E47cs-G apolipoprotein E (APOE) promoter allele is a risk factor for Alzheimer disease of very later onset. Neurosci Lett 326:187-190. CrossRef Medline

Bookheimer S, Burggren A (2009) APOE-4 genotype and neurophysiological vulnerability to Alzheimer's and cognitive aging. Annu Rev Clin Psychol 5:343-362. CrossRef Medline

Chen ZJ, He Y, Rosa-Neto P, Germann J, Evans AC (2008) Revealing modular architecture of human brain structural networks by using cortical thickness from MRI. Cereb Cortex 18:2374-2381. CrossRef Medline

Chung MK, Worsley KJ, Robbins S, Paus T, Taylor J, Giedd JN, Rapoport JL, Evans AC (2003) Deformation-based surface morphometry applied to gray matter deformation. Neuroimage 18:198-213. CrossRef Medline

Corder EH, Saunders AM, Strittmatter WJ, Schmechel DE, Gaskell PC, Small GW, Roses AD, Haines JL, Pericak-Vance MA (1993) Gene dose of apolipoprotein E type 4 allele and the risk of Alzheimer's disease in late onset families. Science 261:921-923. CrossRef Medline

den Heijer T, Oudkerk M, Launer LJ, van Duijn CM, Hofman A, Breteler MM (2002) Hippocampal, amygdalar, and global brain atrophy in different apolipoprotein E genotypes. Neurology 59:746-748. CrossRef Medline

Engqvist L (2005) The mistreatment of covariate interaction terms in linear model analyses of behavioural and evolutionary ecology studies. Anim Behav 70:967-971. CrossRef

Evans AC (2013) Networks of anatomical covariance. Neuroimage 80:489504. CrossRef Medline

Farrer LA, Cupples LA, Haines JL, Hyman B, Kukull WA, Mayeux R, Myers RH, Pericak-Vance MA, Risch N, van Duijn CM (1997) Effects of age, sex, and ethnicity on the association between apolipoprotein E genotype and Alzheimer disease. A meta-analysis. APOE and Alzheimer Disease Meta Analysis Consortium. JAMA 278:1349-1356. CrossRef Medline

Fennema-Notestine C, Panizzon MS, Thompson WR, Chen CH, Eyler LT, Fischl B, Franz CE, Grant MD, Jak AJ, Jernigan TL, Lyons MJ, Neale MC, Seidman LJ, Tsuang MT, Xian H, Dale AM, Kremen WS (2011) Presence of ApoE epsilon4 allele associated with thinner frontal cortex in middle age. J Alzheimers Dis 26 [Suppl 3]:49-60. CrossRef Medline

Gong G, He Y, Chen ZJ, Evans AC (2012) Convergence and divergence of thickness correlations with diffusion connections across the human cerebral cortex. Neuroimage 59:1239-1248. CrossRef Medline

He Y, Chen Z, Evans A (2008) Structural insights into aberrant topological patterns of large-scale cortical networks in Alzheimer's disease. J Neurosci 28:4756-4766. CrossRef Medline

Honea RA, Vidoni E, Harsha A, Burns JM (2009) Impact of APOE on the healthy aging brain: a voxel-based MRI and DTI study. J Alzheimers Dis 18:553-564. CrossRef Medline

Kabani N, Le Goualher G, MacDonald D, Evans AC (2001) Measurement of cortical thickness using an automated 3-D algorithm: a validation study. Neuroimage 13:375-380. CrossRef Medline

Kang HJ, Kawasawa YI, Cheng F, Zhu Y, Xu X, Li M, Sousa AM, Pletikos M, Meyer KA, Sedmak G, Guennel T, Shin Y, Johnson MB, Krsnik Z, Mayer S, Fertuzinhos S, Umlauf S, Lisgo SN, Vortmeyer A, Weinberger DR, et al. (2011) Spatio-temporal transcriptome of the human brain. Nature 478: 483-489. CrossRef Medline

Kim JS, Singh V, Lee JK, Lerch J, Ad-Dab'bagh Y, MacDonald D, Lee JM, Kim SI, Evans AC (2005) Automated 3-D extraction and evaluation of the inner and outer cortical surfaces using a Laplacian map and partial volume effect classification. Neuroimage 27:210-221. CrossRef Medline

Lambert JC, Pasquier F, Cottel D, Frigard B, Amouyel P, Chartier-Harlin MC (1998a) A new polymorphism in the APOE promoter associated with risk of developing Alzheimer's disease. Hum Mol Genet 7:533-540. CrossRef Medline

Lambert JC, Berr C, Pasquier F, Delacourte A, Frigard B, Cottel D, Pérez-Tur J, Mouroux V, Mohr M, Cécyre D, Galasko D, Lendon C, Poirier J, Hardy 
J, Mann D, Amouyel P, Chartier-Harlin MC (1998b) Pronounced impact of Th1/E47cs mutation compared with - 491 AT mutation on neural APOE gene expression and risk of developing Alzheimer's disease. Hum Mol Genet 7:1511-1516. CrossRef Medline

Lambert JC, Brousseau T, Defosse V, Evans A, Arveiler D, Ruidavets JB, Haas B, Cambou JP, Luc G, Ducimetière P, Cambien F, Chartier-Harlin MC, Amouyel P (2000) Independent association of an APOE gene promoter polymorphism with increased risk of myocardial infarction and decreased APOE plasma concentrations-the ECTIM study. Hum Mol Genet 9:57-61. CrossRef Medline

Lambert JC, Araria-Goumidi L, Myllykangas L, Ellis C, Wang JC, Bullido MJ, Harris JM, Artiga MJ, Hernandez D, Kwon JM, Frigard B, Petersen RC, Cumming AM, Pasquier F, Sastre I, Tienari PJ, Frank A, Sulkava R, Morris JC, St Clair D, et al. (2002) Contribution of APOE promoter polymorphisms to Alzheimer's disease risk. Neurology 59:59-66. CrossRef Medline

Lambert JC, Coyle N, Lendon C (2004) The allelic modulation of apolipoprotein E expression by oestrogen: potential relevance for Alzheimer's disease. J Med Genet 41:104-112. CrossRef Medline

Lambert JC, Mann D, Richard F, Tian J, Shi J, Thaker U, Merrot S, Harris J, Frigard B, Iwatsubo T, Lendon C, Amouyel P (2005) Is there a relation between APOE expression and brain amyloid load in Alzheimer's disease? J Neurol Neurosurg Psychiatry 76:928-933. CrossRef Medline

Laws SM, Hone E, Gandy S, Martins RN (2003) Expanding the association between the APOE gene and the risk of Alzheimer's disease: possible roles for APOE promoter polymorphisms and alterations in APOE transcription. J Neurochem 84:1215-1236. CrossRef Medline

Lemaîitre H, Crivello F, Dufouil C, Grassiot B, Tzourio C, Alpérovitch A, Mazoyer B (2005) No epsilon4 gene dose effect on hippocampal atrophy in a large MRI database of healthy elderly subjects. Neuroimage 24:12051213. CrossRef Medline

Lerch JP, Evans AC (2005) Cortical thickness analysis examined through power analysis and a population simulation. Neuroimage 24:163-173. CrossRef Medline

Lerch JP, Pruessner JC, Zijdenbos A, Hampel H, Teipel SJ, Evans AC (2005) Focal decline of cortical thickness in Alzheimer's disease identified by computational neuroanatomy. Cereb Cortex 15:995-1001. CrossRef Medline

Lerch JP, Worsley K, Shaw WP, Greenstein DK, Lenroot RK, Giedd J, Evans AC (2006) Mapping anatomical correlations across cerebral cortex (MACACC) using cortical thickness from MRI. Neuroimage 31:9931003. CrossRef Medline

Lerch JP, Pruessner J, Zijdenbos AP, Collins DL, Teipel SJ, Hampel H, Evans AC (2008) Automated cortical thickness measurements from MRI can accurately separate Alzheimer's patients from normal elderly controls. Neurobiol Aging 29:23-30. CrossRef Medline

Lescai F, Chiamenti AM, Codemo A, Pirazzini C, D’Agostino G, Ruaro C, Ghidoni R, Benussi L, Galimberti D, Esposito F, Marchegiani F, Cardelli M, Olivieri F, Nacmias B, Sorbi S, Tagliavini F, Albani D, Martinelli Boneschi F, Binetti G, Santoro A, et al. (2011) An APOE haplotype associated with decreased epsilon 4 expression increases the risk of late onset Alzheimer's disease. J Alzheimers Dis 24:235-245. CrossRef Medline

Lyttelton OC, Karama S, Ad-Dab'bagh Y, Zatorre RJ, Carbonell F, Worsley K, Evans AC (2009) Positional and surface area asymmetry of the human cerebral cortex. Neuroimage 46:895-903. CrossRef Medline

Maloney B, Ge YW, Petersen RC, Hardy J, Rogers JT, Pérez-Tur J, Lahiri DK (2010) Functional characterization of three single-nucleotide polymorphisms present in the human APOE promoter sequence: differential ef- fects in neuronal cells and on DNA-protein interactions. Am J Med Genet B Neuropsychiatr Genet 153B:185-201. CrossRef Medline

Mielke MM, Vemuri P, Rocca WA (2014) Clinical epidemiology of Alzheimer's disease: assessing sex and gender differences. Clin Epidemiol 6:37-48. CrossRef Medline

Panizzon MS, Fennema-Notestine C, Eyler LT, Jernigan TL, Prom-Wormley E, Neale M, Jacobson K, Lyons MJ, Grant MD, Franz CE, Xian H, Tsuang M, Fischl B, Seidman L, Dale A, Kremen WS (2009) Distinct genetic influences on cortical surface area and cortical thickness. Cereb Cortex 19:2728-2735. CrossRef Medline

Raznahan A, Lerch JP, Lee N, Greenstein D, Wallace GL, Stockman M, Clasen L, Shaw PW, Giedd JN (2011) Patterns of coordinated anatomical change in human cortical development: a longitudinal neuroimaging study of maturational coupling. Neuron 72:873-884. CrossRef Medline

Rusinek H, Endo Y, De Santi S, Frid D, Tsui WH, Segal S, Convit A, de Leon MJ (2004) Atrophy rate in medial temporal lobe during progression of Alzheimer disease. Neurology 63:2354-2359. CrossRef Medline

Schmitt JE, Lenroot RK, Wallace GL, Ordaz S, Taylor KN, Kabani N, Greenstein D, Lerch JP, Kendler KS, Neale MC, Giedd JN (2008) Identification of genetically mediated cortical networks: a multivariate study of pediatric twins and siblings. Cereb Cortex 18:1737-1747. CrossRef Medline

Shaw P, Lerch JP, Pruessner JC, Taylor KN, Rose AB, Greenstein D, Clasen L, Evans A, Rapoport JL, Giedd JN (2007) Cortical morphology in children and adolescents with different apolipoprotein $\mathrm{E}$ gene polymorphisms: an observational study. Lancet Neurol 6:494-500. CrossRef Medline

Sled JG, Zijdenbos AP, Evans AC (1998) A nonparametric method for automatic correction of intensity nonuniformity in MRI data. IEEE Trans Med Imaging 17:87-97. CrossRef Medline

Sowell ER, Peterson BS, Kan E, Woods RP, Yoshii J, Bansal R, Xu D, Zhu H, Thompson PM, Toga AW (2007) Sex differences in cortical thickness mapped in 176 healthy individuals between 7 and 87 years of age. Cereb Cortex 17:1550-1560. CrossRef Medline

Taylor JE, Adler RJ (2003) Euler characteristics for Gaussian fields on manifolds. Ann Probab 31:533-563. CrossRef

Tohka J, Zijdenbos A, Evans A (2004) Fast and robust parameter estimation for statistical partial volume models in brain MRI. Neuroimage 23:84-97. CrossRef Medline

Visser PJ, Verhey FR, Hofman PA, Scheltens P, Jolles J (2002) Medial temporal lobe atrophy predicts Alzheimer's disease in patients with minor cognitive impairment. J Neurol Neurosurg Psychiatr 72:491-497. Medline

Wang L, Li H, Liang Y, Zhang J, Li X, Shu N, Wang YY, Zhang Z (2013) Amnestic mild cognitive impairment: topological reorganization of the default-mode network. Radiology 268:501-514. CrossRef Medline

Xie S, Zhang Z, Zhao Q, Zhang J, Zhong S, Bi Y, He Y, Pan H, Gong G (2014) The effects of $\mathrm{X}$ chromosome loss on neuroanatomical and cognitive phenotypes during adolescence: a multi-modal structural MRI and diffusion tensor imaging study. Cereb Cortex. Advance online publication. Retrieved May 10, 2014. doi: 10.1093/cercor/bhu079.

Yao Z, Hu B, Liang C, Zhao L, Jackson M, Alzheimer's Disease Neuroimaging I (2012) A longitudinal study of atrophy in amnestic mild cognitive impairment and normal aging revealed by cortical thickness. PLoS One 7:e48973. CrossRef Medline

Ye S, Dunleavey L, Bannister W, Day LB, Tapper W, Collins AR, Day IN, Simpson I, Southampton Atherosclerosis S (2003) Independent effects of the $-219 \mathrm{G}>\mathrm{T}$ and epsilon 2/epsilon 3/epsilon 4 polymorphisms in the apolipoprotein E gene on coronary artery disease: the Southampton Atherosclerosis Study. Eur J Hum Genet 11:437-443. CrossRef Medline 